\title{
Modelling of Manhattan K-Nearest Neighbor for Exhaust Emission Analysis of CNG-Diesel Engine
}

\author{
T. Sathish ${ }^{1 \dagger}$ and A. Muthulakshmanan ${ }^{2}$ \\ ${ }^{1}$ Vesta Research Institute, Aranthangi, Tamil Nadu, India \\ ${ }^{2}$ Department of Mechanical Engineering, Vaagdevi College of Engineering, Warangal, Telangana, India
}

†Corresponding Author Email: sathish.sailer@gmail.com

(Received May 15, 2018; accepted July 18, 2018)

\begin{abstract}
Hybrid fuel for the operation of diesel engine is the motivated research in this study. The diesel engine is modified to operate with the hybrid diesel and compressed natural gas (CNG). In this work a four stroke, single cylinder diesel engine is considered to operate at variable load and speed. At is operation condition the emission characteristics are measured to model the proposed Manhattan K-nearest neighbor (MKNN) technique. The MKNN is modelled to effectively analysis and predict the torque, brake power, exhaust emissions and break specific fuel consumption (BSFC). The MKNN is modelled with the constant $\mathrm{K}=3$ and applied Manhattan distance formula for neighbor determination. From the result analysis it is evident that the proposed MKNN technique can effectively predict the engine performance and exhaust emission while the usage of hybrid fuel.
\end{abstract}

Keywords: Hybrid fuel system; Compressed natural gas; Manhattan K-Nearest Neighbor; Manhattan distance; Diesel engine emission.

\section{INTRODUCTION}

Now a day's eco-friendly engines are suggested to use in automobiles and industries for prevent environmental hazards. In this sense usage of natural fuel become one of the suitable options for the eco-friendly engine design. Compressed natural gas CNG is the most used alternative fuel for Internal Combustion engines, and it is proved that the IC engine with CNG can effectively reduce the environmental population (Ghobadian et al. 2009; Yusaf et al. 1996; D’Amberosio et al. 2005). The usage of CNG in IC engines can also minimize the noise and vibration and enhance the brake thermal efficiency (Murata $\mathrm{H}$ 2000). While replacing the conventional fuel with the natural gas in commercial vehicles like, bus, passenger cars and heavy trucks provides numerous benefits some of them are (Cascetta et al. 2008; Fritz \& Egbuonu, 1992; Gandhidasan et al. 1991);

$\checkmark$ Particulate matter emissions can be significantly reduced.

$\checkmark$ Maintenance and wear costs can be reduced.

$\checkmark$ Also effectively reduces NOx emission
In the proposed paper, the single cylinder diesel engine is modified, so that it can operate on the both diesel as well as natural gas. The modified engine acts as dual fuel engine system can provide better performance. The following alteration is made to change the fuel compatibility of the engine; the compression ratio of the engine is reduced to prevent knock phenomena. A CNG injection is installed and modified the diesel injection system; and some minor modifications (Jonsson, 2000). A finite volume commercial CFD package is utilized to design Venturi mixer. (Sivakumar et al. 2017, Sathish 2017; Sathish and Jayaprakash, J. 2017; Sathish and Muthulakshmanan 2018; Sathish and Jayaprakash, 2015)

Testing modified engines under all possible operating conditions and fuel cases was considered to be both time consuming and expensive. Thus artificial intelligence technique is adapted to test all the engines under all the possible operating conditions. In this paper a Manhattan K nearest neighbor is proposed for the effective prediction of modified diesel engine to operate with hybrid diesel and CNG fuel. 


\section{RELATED WORK}

Some of the recent work related to the usage of compressed natural gas fuel for the diesel engine is briefed below;

Salahi et al. (2017), have presented the effect of using a pre-chamber to extend some operating ranges in a Reactivity Controlled Compression Ignition engine. They also investigated the engine using coupled multidimensional computational fluid dynamics (CFD) with detailed chemical kinetic mechanisms. Heping Song et al. (2017), have presented a comparison of using diesel and polyoxymethylene dimethyl ethers (PODEn) as pilot fuels for natural gas DF combustion. Abhishek Paul et al. (2017), have investigated the effect of diesel, ethanol, and diethyl ether (DEE) blends on performance, combustion, and emission of singlecylinder compression ignition engine. Srinivasan (2017) studied and analysed about the missile with grid fins and the effect on flow drag using ANSYS. Godwin (2017) and Lakshmanan (2017) investigated about the optimum parameters for obtaining the best performance using alternate fuels of IC engines working under the current cooling system using Nanofluids.

\section{EXPERIMENTAL INVESTIGATION}

A single cylinder four stroke high speed diesel engine is modified to operate with hybrid dieselCNG fuel is designed in the proposed work. The proposed modification on diesel engine is encouraged to reduce the environmental hazard. The main specification of the modified engine is given in table 1 . The main idea for the major and minor modification of the diesel engine is referred from ref. (Yusaf 2009; Talal et al. 2010).

\section{PROPOSED MANHATTAN K NEAREST NEIGHBOR}

The K- Nearest neighbor is the straight forward classifier with greater accuracy. The classification in this algorithm depends upon the Manhattan similarity measure. The continuity of attributes is very much important in this process. The progression stages in the nearest neighbor algorithm are shown in figure 1.

Table 1 Specifications of the test engine

\begin{tabular}{|c|c|}
\hline Engine type & $\begin{array}{c}\text { Y170f vertical 4 stroke } \\
\text { diesel engine }\end{array}$ \\
\hline Bore & $70 \mathrm{~mm}$ \\
\hline Stroke & $55 \mathrm{~mm}$ \\
\hline Displacement & $211 \mathrm{~mm}$ \\
\hline Engine speed & $3600 \mathrm{rpm}(\mathrm{max})$ \\
\hline Max. power & $3.5(\mathrm{~kW})$ \\
\hline Continuous power & $3.13(\mathrm{~kW})$ \\
\hline Compression ratio & $16: 1$ \\
\hline Cooling system & Air cooled \\
\hline Combustion system & Direct injection \\
\hline
\end{tabular}

RMSE $=\left(\frac{\sum_{j}^{n}\left(t_{j}-o_{j}\right)}{n}\right)$

$M R E=\frac{1}{n} \sum_{1}^{n}\left|100 * \frac{\left(t_{j}-p_{j}\right)}{t_{j}}\right|$

The present work uses MKNN modelling to predict the relationship of brake power, brake specific fuel consumption, torque, emission components and brake thermal efficiency with the engine speed and percentage CNG as inputs. The MKNN is modelled with two inputs and nine outputs, which were obtained from the experimental analysis.

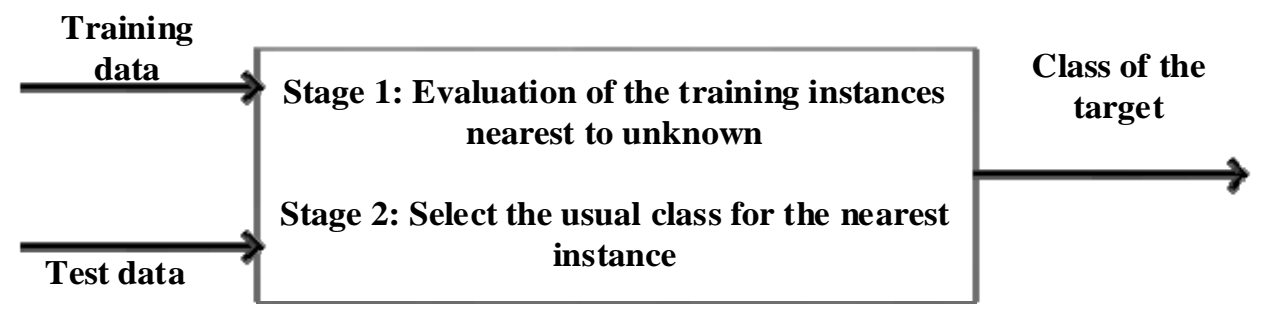

Fig. 1. MKNN classification with training and test data input for progression

Table 2 Performance value by proposed technique

\begin{tabular}{|c|c|c|c|c|c|c|c|c|}
\hline $\begin{array}{c}\text { Operating } \\
\text { Condition }\end{array}$ & Torque & BTE $\mu_{\text {th }}$ & BSFC & $\begin{array}{c}\text { Exhaust } \\
\text { Temperature }\end{array}$ & $\mathrm{CO}$ & $\mathrm{CO}_{2}$ & $\mathrm{NOx}$ & $\mathrm{O}_{2}$ \\
\hline 1 & 11 & 28 & 222 & 203 & 21 & 2 & 22 & 12 \\
\hline 2 & 18 & 31 & 236 & 240 & 43 & 3 & 36 & 14 \\
\hline 3 & 24 & 35 & 254 & 290 & 85 & 6 & 54 & 15 \\
\hline 4 & 29 & 36 & 278 & 320 & 92 & 7 & 87 & 18 \\
\hline 5 & 34 & 39 & 298 & 395 & 118 & 8 & 99 & 21 \\
\hline
\end{tabular}




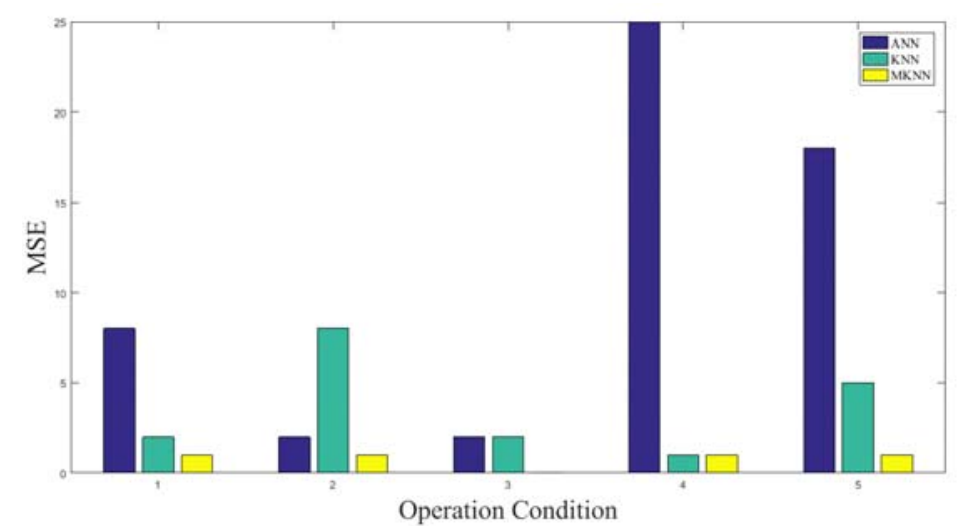

Fig. 2. Mean Square Error Comparison

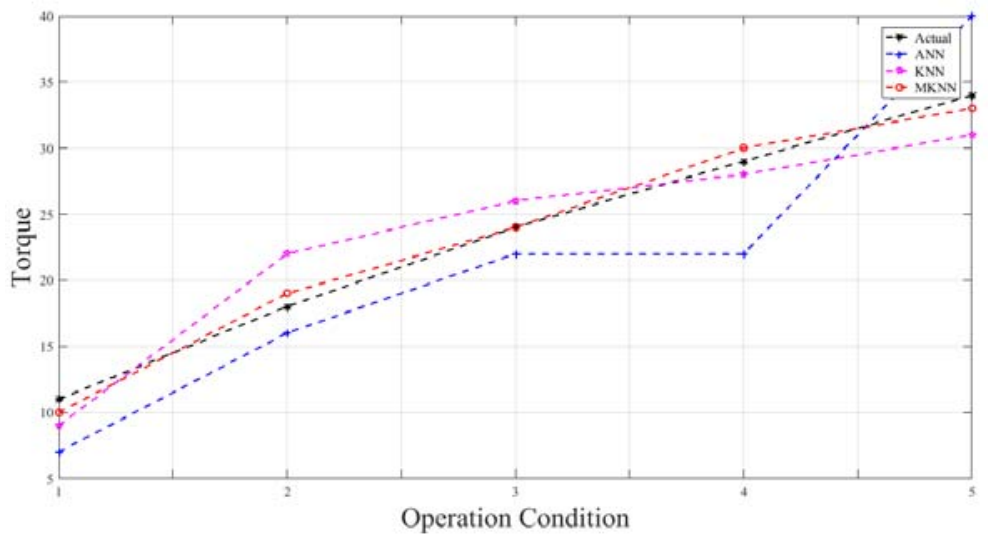

Fig. 3. Comparison of Torque (Nm)

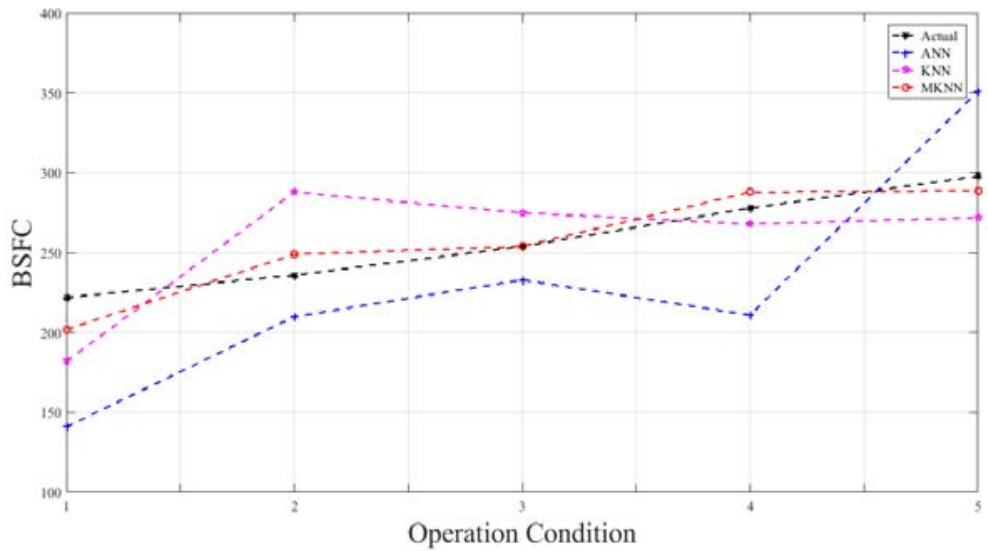

Fig. 4. Comparison of BSFC (g/kW.hr)

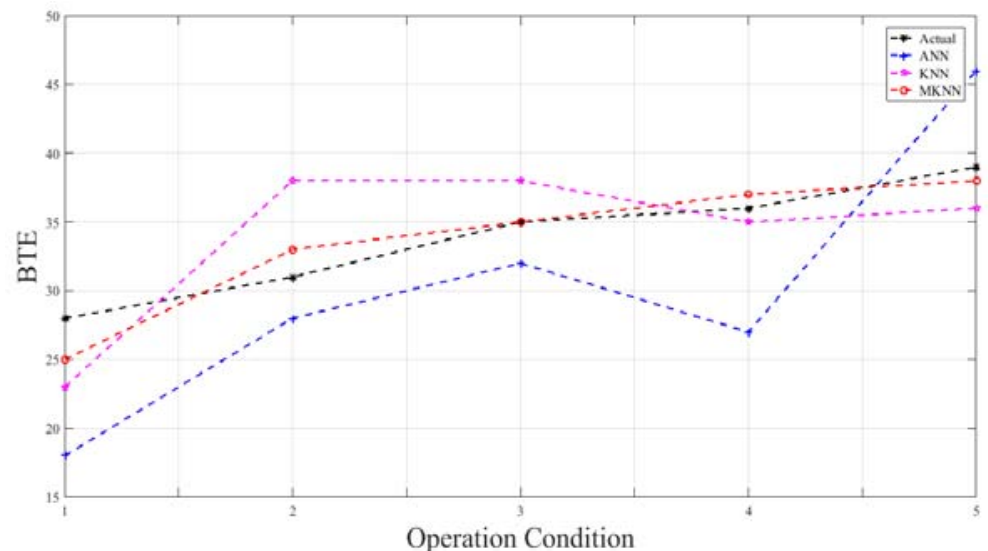

Fig. 5. Comparison of BTE $\mu^{\text {th }}(\%)$ 
T. Sathish and A. Muthulakshmanan /JAFM, Vol. 11, Special Issue, pp. 39-44, 2018.

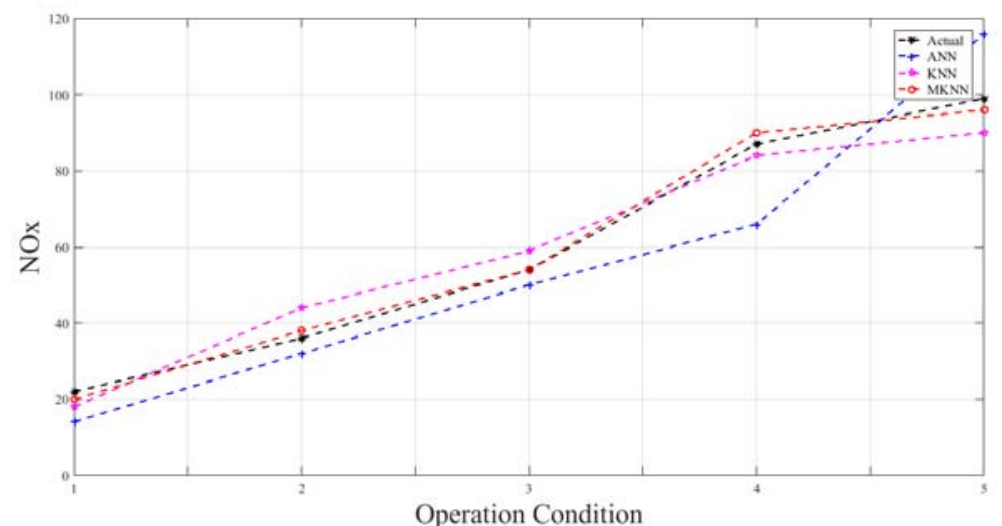

Fig. 6. Comparison of $\mathrm{NO}_{x}(\mathrm{PPM})$

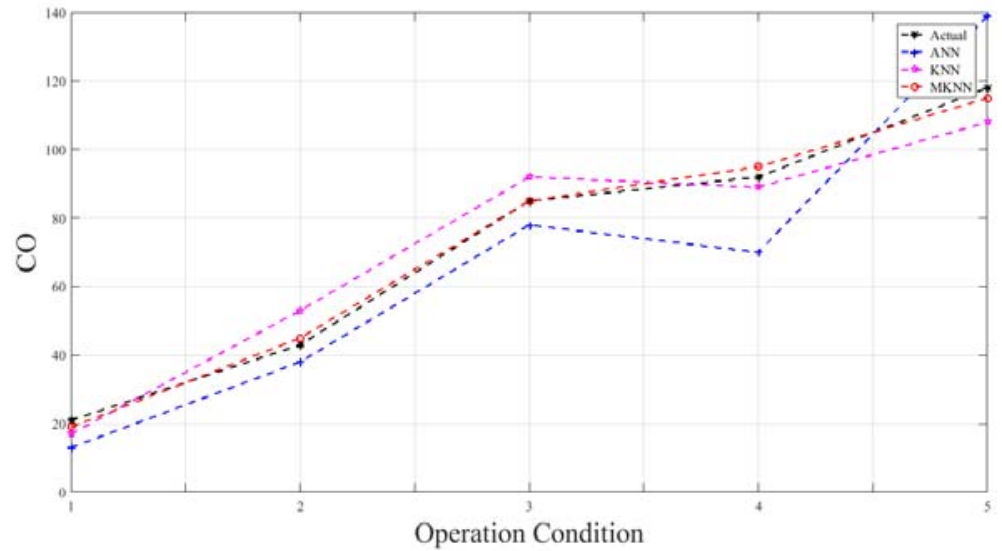

Fig. 7. Comparison of $\mathrm{CO}(\%)$

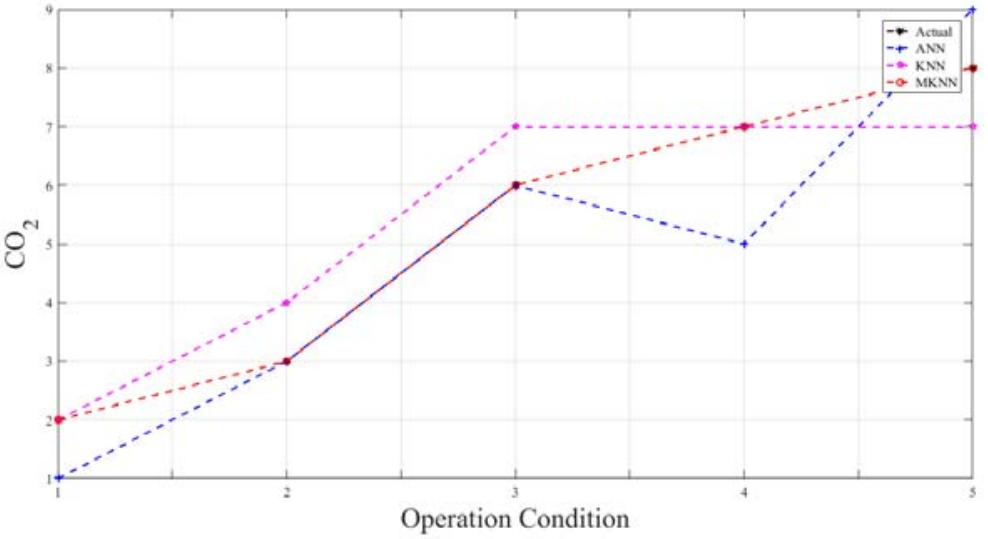

Fig. 8. Comparison of $\mathrm{CO}_{2}(\%)$

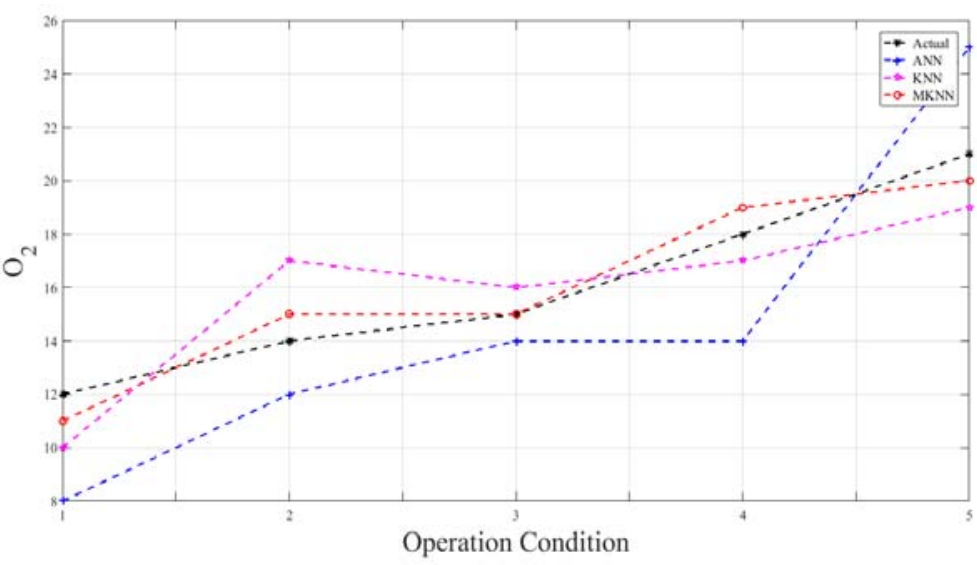

Fig. 9. Comparison of $\mathrm{O}_{2}(\%)$ 


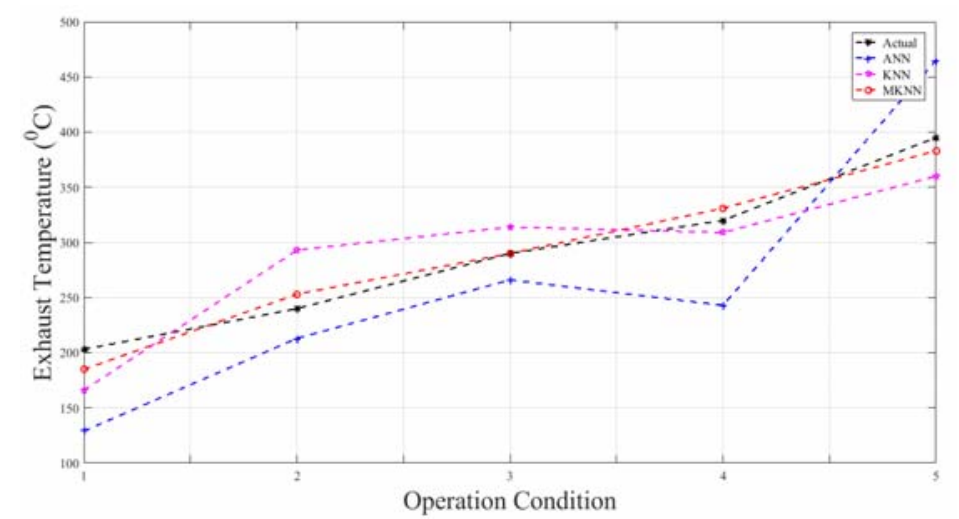

Fig. 10. Comparison of Exhaust Temperature $\left(0^{\mathrm{C}}\right)$

\section{RESULTS AND DISCUSSION}

The proposed MKNN technique is modelled to analysis the testing performance of the modified diesel engine. The MKNN technique is modelled with two inputs and nine outputs and implemented in the matlab 2016a in windows platform. The prediction accuracy is evaluated by comparing the actual value with the predicted value. The obtained performance is given in table 2 and is plotted in the graphs given in fig 2 to fig 10 .

So far performance analysis proved that the proposed MKNN technique provided better performance than the conventional prediction techniques such as ANN and KNN. Moreover the proposed technique predict the value which is closer to the actual value. Hence the proposed technique will become a better option for the analysis of modified diesel engine.

\section{CONCLUSION}

The hybrid fuel system for the modified diesel engine provided better eco-friendly performance and motivated to reduce the environmental hazard. The proposed hybrid fuel system combines both diesel and compressed natural gas. The diesel engine is suggested to modify its diesel injection system and install natural gas injection system. A novel Manhattan K nearest neighbor $r$ technique is modelled to test the performance of the modified diesel engine. The performance evaluation proves that the proposed MKNN technique effectively analyzed the test performance and provided better prediction accuracy.

\section{REFERENCES}

Cascetta, F., G. Rotondo and M. Musto (2008). Measuring of compressed natural gas in automotive application: a comparative analysis of mass versus volumetric metering methods. Flow Measurement and Instrumentation 19(1), 338-341.

D’Amberosio, S., E. Spessa, and A. Vassallo
(2005). Methods for specific emission evaluation in spark ignition engines based on calculation procedures of air-fuel ratio: development, assessment, and critical comparison. Journal of Engineering Gas Turbines Power 127(1), 869-881.

Fritz, S. G., and R. I. Egbuonu, (1992). Emission from heavy duty trucks converted to CNG. $J$ Eng Gas Turbine Power 114(1), 561-567.

Gandhidasan, P., A. Ertas, and E. E. Anderson, (1991). Review of methanol and compressed natural gas (CNG) as alternative for transportation fuels. Journal of Energy Research and Technology 113 (1), 101-107.

Ghobadian, B., M. Rahimi, A. M. Nikbakht, G. Najafi, and F. T. Yusaf (2009). Diesel engine performance and exhaust emission analysis using waste cooking biodiesel fuel with an artificial neural network. Renewable Energy 34(4), 976-982.

Jonsson, O. (2000). Introduction of the first heavy $N G V$ trucks in Sweden. In: 7th international conference and exhibition on natural gas vehicles, 17-19, Yokohama, Japan.

Murata, H. (2000). Example of introducing compressed natural gas vehicle, In: 7th international conference and exhibition on natural gas vehicles. 17-19, Yokohama, Japan.

Paul, A., Panua, R. S., Debroy, D. and Bose, P. K. (2017). Effect of diethyl ether and ethanol on performance, combustion, and emission of single-cylinder compression ignition engine. International Journal of Ambient Energy 38(1), 2-13.

Salahi, M. M., V. Esfahanian, A. Gharehghani, and M. Mirsalim (2017). Investigating the reactivity controlled compression ignition (RCCI) combustion strategy in a natural gas/diesel fueled engine with a pre-chamber. Energy Conversion and Management 132(1), 40-53. 
T. Sathish and A. Muthulakshmanan /JAFM, Vol. 11, Special Issue, pp. 39-44, 2018.

Sathish, T. (2017). Performance Measurement on Extracted Bio-Diesel from Waste Plastic. Journal of Applied Fluid Mechanics 10, 41-50.

Sathish, T., and A. Muthulakshmanan (2018). Design and Simulation of Connecting Rods with Several Test Cases Using Al Alloys and High Tensile Steel. International Journal of Mechanical and Production Engineering Research and Development 8(1), 1119-1126.

Sathish, T., and J. Jayaprakash (2015). MetaHeuristic Approach to Solve Multi Period Disassembly-To-Order Problem of End-OfLife Products using Adaptive Genetic Algorithm. International Journal of Mechanical \& Mechatronics Engineering 15(3), 59-67.

Sathish, T., and J. Jayaprakash (2017). Multi period disassembly-to-order of end-of-life product based on scheduling to maximise the profit in reverse logistic operation. International Journal of Logistics Systems and Management 26(3), 402-419.

Sivakumar, V., K. Visagavel and A. Selvakumar (2017). Analysis of Ventilation Rate in Cross Ventilated Rooms by Varying Aperture Shape of Windows using CFD. Journal of Applied Fluid Mechanics 10, 61-68.

Song, H., C. Liu, F. Li, Z. Wang, X. He, S. Shuai, and J. Wang (2017). A comparative study of using diesel and PODEn as pilot fuels for natural gas dual-fuel combustion. Fuel 188(1), 418-426.

Yusaf, T. F., A. H. Shamsuddin, Y. Ali and A. F. Ismail (1996). Design modification of high speed diesel engine to accommodate compressed natural gas. International Energy Journal 18(1),

19-26. 